\title{
Investigating Parental Influences on Sixth Graders' Mathematical Identity in Greece: A Case Study
}

\author{
Sonia Kafoussi ${ }^{{ }^{*},}$, Petros Chaviaris ${ }^{1}$, Andreas Moutsios-Rentzos ${ }^{1}$ \\ ${ }^{1}$ University of the Aegean, GREECE \\ *CORRESPONDENCE: $\triangle$ kafoussi@aegean.gr
}

\begin{abstract}
In this paper, we present a qualitative study about the parental influences on sixth graders' mathematical identity. The case study was conducted in a Greek primary school where fifteen children were interviewed through a series of questions for each of the following axes: attainment, attitudes, values, nature of mathematics, self-confidence and child-parent collaboration for homework, in line with the tri-focused model of Abreu and Cline (2003).The analyses drew upon two directions a) the students' positioning and, b) the types of students' resources. The results of the conducted analyses revealed qualitative differences with respect to the students' selfidentification; between those who are self-identified as 'good' at mathematics and those who identified themselves as being 'average' at mathematics. According to our results the parental influences on the construction of the students' mathematical identity at home is interwoven with their interaction with their parents. The students expressed positive dispositions and beliefs about their ability to participate and perform effectively in mathematical tasks when they collaborated with their parents at home in an environment of confidence.
\end{abstract}

Keywords: mathematical identity, parental influences, primary education, case study

\section{INTRODUCTION}

The interest of mathematics education researchers has been lately increased concerning the investigation of the relationships between in-school mathematics learning and the out-of-school broader socio-cultural environment. This interest is related to the socio-cultural approaches to mathematics education and is in line with the attempt to gain deeper understanding of the identified variation in the students' learning mathematics with respect to their socio-cultural background (Abreu, 1995). It is well known that the children participate in discourse practices linked with mathematics learning in the family, in the school unit and in the broader social context of their community (Abreu, 1995). The learning route of a child in mathematics does not depend only by facts realizing in the school classroom but also it is influenced by facts outside it. Within this perspective, various studies have highlighted the relationship between the parents' involvement and their children's mathematical experience in primary education (Abreu, Cline, \& Shamsi, 2002; Anderson, 1997; Bratton, Civil \& Quintos, 2005; Cao, Bishop, \& Forgasz, 2006; Crafter, 2012; Galindo \& Sheldon, 2012; Hepworth-Berger, 2004; Hyde, Else-Quest, Alibali, Knuth, \& Romberg, 2006; Knapp, Landers, Liang, \& Jefferson, 2017; Lang \& Meaney, 2011; Moutsios-Rentzos, Chaviaris, \& Kafoussi, 2015; Wang, 2004). More specifically, the students' family crucially affects their interaction with school mathematics, through the students' everyday homework and through the family's broader beliefs, attitudes, emotions and practices about mathematics as experienced in everyday mathematically related (implicitly or explicitly) activities. Moreover, research evidence has shown that the ways through which a person develops his or her

Article History: Received 4 September $2019 \bullet$ Revised 7 November $2019 \bullet$ Accepted 7 November 2019

(C) 2020 by the authors; licensee Modestum Ltd., UK. Open Access terms of the Creative Commons Attribution 4.0 International License (http://creativecommons.org/licenses/by/4.0/) apply. The license permits unrestricted use, distribution, and reproduction in any medium, on the condition that users give exact credit to the original author(s) and the source, provide a link to the Creative Commons license, and indicate if they made any changes. 
mathematical competence in different social practices (for example, in school or in family daily life) are usually characterized by discontinuity and the students' school mathematical practice does not imply their performing in out of school relevant practices, especially for groups not belonging to the dominant social group, such as immigrant groups (Abreu, Gorgorio, \& Boistrup, 2018; Takeuchi, 2018). On the other hand, some researchers have mentioned that such discontinuities should not be viewed as obstacles, but as a variety of practices that the students can negotiate in participating in classroom activities (Hodge \& Cobb, 2018).

In our research, we posit that the study of the parents-children interactions in mathematics is crucial in the construction of students' identity linked with mathematics. Although we didn't focus on particular groups of students, we adopt the view that school and family culture constitute a network of interacting practices that form dynamic affect systems (Pepin \& Roesken-Winter, 2015) that includes amongst others attitudes, beliefs, values and self-confidence, which crucially influences the students' mathematical identity. Considering Greece where this study was conducted, it appears that a major part of parental involvement about children's learning focuses on mathematics, since the Greek parents spend more time with their children at home for mathematics in comparison with the other courses (Kafoussi, 2006). Consequently, the role of the parents seems to be crucial in shaping their children's cognitive and affective relationship with mathematics, thus rendering important to investigate the links between parental involvement and their mathematical identity with the purpose to improve mathematics education through appropriately designed school-family interactions. Thus, in the present study, we concentrate on the perceived by primary school students' parental involvement about mathematics in Greece in order to identify aspects of parental involvement that are crucial for the children's relationship with mathematics.

\section{THEORETICAL BACKGROUND}

The notion of identity has been widely discussed in mathematics education research over the past two decades (for example, Abreu \& Cline, 2003; Anderson, 2007; Crafter \& Abreu, 2010; Darragh, 2016; Graven \& Heyd-Metzuyanim, 2019; Radovic, Black, Williams \& Salas, 2018; Sfard \& Prusak, 2005; Wenger, 1998). Sfard and Prusak (2005) have argued that the notion of identity can be used as a tool for investigating learning as a culturally shaped activity and referred to this as the "missing link" in the "complex dialectic between learning and its sociocultural context" (p. 15). However, it is also clear that there is a variety of views of identity and researchers often choose ideas from a number of different viewpoints (Darragh, 2016; Graven \& Heyd-Metzuyanim, 2019; Radovic et al., 2018). In our research, we agree with Martin's (2007) conceptualisation of mathematical identity, referring to:

"the dispositions and deeply held beliefs that individuals develop about their ability to participate and perform effectively in mathematical contexts and to use mathematics to change the conditions of their lives. A mathematics identity encompasses a person's selfunderstandings and how they are seen by others in the context of doing mathematics" ( $p$. 150).

Moreover, we accept the Median notion of identity in which a main characteristic includes its constant construction through interactions amongst people, connected with questions concerning the links between personal worlds and collective discourses (Darragh, 2016; Graven \& Heyd-Metzuyanim, 2019). More specifically, mathematical identity is constructed through the individuals' participation in different communities of practice, including school classrooms, family context and the broader community. These communities of practice - because of their organization, their habits and conventions- provide the participants different levels of engagement and thus support in diverse ways the construction of identities (Nasir \& Hand, 2008). Consequently, mathematical identity may manifest differently in school and at home. So, the study of the construction of the students' mathematical identity requires recognition of all its aspects and complex paths. Therefore, in our research we investigated the parental influences on the construction of their children's mathematical identity, focussing on how children perceive parental involvement in their mathematical life.

Furthermore, mathematical identity relates to how one participant presents oneself to others and position oneself among the others through his/her choices and perceptions and how the others position him/her in a community (Turner, Dominguez, Maldonado, \& Empson, 2013; Wagner \& Herbel-Eisenmann, 2009). Abreu and Cline (2003) posited that the students' mathematical identity incorporates three complementary positioning processes: a) identifying the other, b) being identified, and c) self-identification. "Identifying the other" concerns individual's understanding of social identities of others, "being identified" concerns individual's understanding of identities extended to themselves by others, and "self-identification" refers to 
the internalized and individual level of identity. This tri-focussed model of Abreu and Cline helped us to investigate the students' positioning about their parental involvement in mathematics.

Finally, researchers have identified various types of resources when they investigate the ways that subjects interpret their positioning about something. For example, Crafter (2012) investigated the resources that parents from different cultural backgrounds used in order to understand the mathematical achievement of their children. She mentioned that the concept of "resource" refers to "something which one resorts to for aid or support" (p. 34). Crafter (2012, p. 34) classified resources as being: a) tangible (based on "something 'factual' or "knowledgeable", such as grades or exam scores), or b) intangible (based on ideas that are "abstract or representational" such as the "parents' construction of child development"). In her research she identified three dominant resources that parents used: the teacher, exam test results and constructions of child development. However, all these resources were interpreted by the parents in different ways according to the parents' cultural models and this issue could cause misunderstandings between home and school. More recently, Ntow and Adler (2019), in a study about mathematics teaching identities, employed the three types of resources identified by Nasir and Cooks (2009, p. 44): "material resources (the physical artifacts in the setting), relational resources (interpersonal connections to others in the setting), and ideational resources (ideas about oneself and one's relationship to and place in the practice and the world, as well as ideas about what is valued and what is good)". In our study, we located the types of students' resources about their parental involvement at mathematics according to the broader theoretical context that exists in mathematics education about this topic as it is presented below.

\section{Parental Involvement in School-family Interaction in Mathematics}

Parental involvement has been differentiated between indirect parental involvement and direct parental involvement (Cai, Moyer, \& Wang, 1997). Indirect parental involvement includes the family expectations with respect to the student's mathematical attainment, the parental attitudes towards mathematics, the broader family encouragement and support of the students through a variety of material (for example, books or educational software) or immaterial means (for example, guidance about mathematical related or affected professional prospects). Direct parental involvement refers to the immediate parents-children interactions that include their interaction in mathematics homework, as well as a variety of formal or informal mathematically related activities.

Regarding indirect parental involvement, studies suggest that the parents' views about the value of mathematics affect their children's attitude towards mathematics, whilst the parents' high expectations about their children mathematical attainment appear to positively affect both their attainment and their self-esteem or self-confidence (Jacobs \& Bleeker, 2004; Wang, 2004) from their early years of schooling (Galindo \& Sheldon, 2012). Moreover, considering the broader family support for the children's learning mathematics (such as number of books at home), it appears that it is positively linked with their attainment (Hyde et al., 2006; Wang, 2004). Regarding direct parental involvement, research findings suggest that the quality of the collaboration between parents and students -rather than the mere amount of the time spent- crucially determines the effectiveness of parental involvement on the students' preparing their homework (Hyde et al., 2006; Pezdek, Berry, \& Renno, 2002).

Moreover, Cao, Bishop and Forgasz (2006) in a large study conducted in China and Australia with students aged 11, 13 and 15 years old identified variations in the students' perceived parental involvement about mathematics linked with the students' age, country of residence and language. In specific, they found that the perceived parental involvement decreases as the students' age increases and concentrating within each country of residence, the socio-cultural identity of the students appeared to be linked with the perceived parental involvement. Furthermore, mathematics education research projects suggest that when considering students who are not in the dominant socio-cultural community of a country the parental involvement is a crucial factor for their appropriate social integration (Abreu et al., 2002; Crafter, 2012; Moutsios-Rentzos et al., 2015). Furthermore, Abreu et al. (2002) studied the parental support to their children's transitions between school mathematics and mathematics at home revealing that the parents' views about their own involvement or not in their children's learning varied depending on the ethnic origin. Consequently, the broader sociocultural environment of a country as well as the specific cultural characteristics of the families appear to affect parental involvement about the students' learning mathematics. 


\section{The Greek Family in and out of School}

Following these, it is important to identify the typical family structure and function in Greece, as well the typical ways of school-family interaction with respect to mathematics. Mylonas, Gari, Giotsa, Pavlopoulos, and Panagiotopoulou (2006, p. 351) have noted that in the last thirty years the "father has lost some of the autocratic power over the mother and the children", which however did not imply a change to "family values associated with maintaining close contact with relatives, children respecting grandparents, children's obligations toward parents". Hence, the "Greek family appears to be phenomenologically a nuclear family" (Mylonas et al., 2006, p. 351), as it includes a married couple and their children (Nova-Kaltsouni, 2018), thus satisfying the definition of the nuclear family of two generations constituting a household. At the same time, the Greek family functionally is characterised as extended family or joint family (more than two generations and/or relatives in the same household), due to the fact that the nuclear family members "maintain close contacts with relatives; they visit them regularly, or if living at some distance, telephone them frequently" (Mylonas et al., 2006, p. 351). Consequently, the morphological equivalent of the Greek family "is the extended family system in the urban setting with a continuation of contacts with its network of kin" (Mylonas et al., 2006, p. 352). Moreover, Nova-Kaltsouni (2018) discusses survey data gathered by the Hellenic Statistical Authority, the Eurostat and the European Social Survey, as well as by various research projects conducted in Greece, identifying that the role of the mother in the upbringing of the children qualitatively differs from the father's, with the mother expected to be the predominant carer, even with respect to her career.

Considering school-family interaction in Greece, it predominantly refers to assessment: formative in the sense of everyday homework and summative in the sense of end of term grades. Furthermore, in these interactions, the mother is mainly involved with helping with her children's homework or with interacting with the school teacher. This is also evident in research projects that investigate the child-parent relationships in Greece, with the mother predominantly participating in such projects. For example, in a study investigating children-parents links with respect to parental involvement, $67 \%$ of the parents who participated were mothers (Moutsios-Rentzos \& Leontiou, 2016). However, in a previous project conducted with primary school students in Greece (Moutsios-Rentzos et al., 2015) concerning the similarities between mother's and father's involvement at mathematics, it was revealed that although within the family unit existed an internally consistent value system about mathematics, the students' perceived role of the mother about mathematics differed from the respective role of the father. The children's perception of their mother as being good at math was positively linked mainly with her helping with difficult mathematics problems at home, while their perception of the father as being good at math had broader positive links with a wider range of mathematical practices (including checking homework frequently, asking about assessment results, encouragement).

Finally, regarding the central role of homework at mathematics, the teachers' worksheets constitute a common form of everyday and important school-family communication in our country as they are consisted of tasks chosen by the teachers and are not included in the students' school mathematics textbooks. They are affected by the teachers' expectations about their students' attainment after their teaching in the classroom and we posit that they also shape to a certain extent the perceptions of parents about the nature of school mathematics and the purposes of their teaching, although they are not officially activities for parent-child collaboration. According to a previous research about the qualitative characteristics of the students' mathematics homework in Greece, it has been founded that the vast majority of the tasks did not have a context, no mathematical task had such a wording which would encourage the students to find more than one solution and all the tasks asked only for the answer itself, with no explicit requirement of the justification of that answer (Kafoussi, Moutsios-Rentzos, \& Chaviaris, 2019).

\section{The Purpose of this Study}

Based on the above theoretical considerations and empirical results, it seems that a fundamental question for mathematics education nowadays concerns the basic characteristics of the family context that support the child's development of a positive relationship with mathematics. In general, there is little research about mathematical identity for primary school students (Radovic et al., 2018). Moreover, in Greece, there appears to be little research addressing research questions regarding parental involvement and the construction of students' mathematical identity. We chose to conduct our investigations including the differentiation between father and mother, as supported by the family structure and function in Greece and the related research findings. Thus, in the tri-focussed model of Abreu and Cline (2003), the "other" is "the mother" and "the father" (and not "the parents"). Furthermore, we drew upon aforementioned research findings about identity and parental involvement from the broader literature to concentrate on six axes of identity: a) mathematics 


\begin{tabular}{|c|c|c|c|}
\hline \multirow[t]{2}{*}{ Identity Axes } & \multicolumn{3}{|c|}{ Identity Foci (with interview items) } \\
\hline & Self-identification & Being identified & $\begin{array}{l}\text { Identifying the other } \\
\text { (mother/father) }\end{array}$ \\
\hline Attainment (ATN) & $\begin{array}{l}\text { Do you believe that you are } \\
\text { good at mathematics? What } \\
\text { makes you believe that? }\end{array}$ & $\begin{array}{l}\text { Does your mother/father believe } \\
\text { that you are good at } \\
\text { mathematics? What makes you } \\
\text { believe that? }\end{array}$ & $\begin{array}{l}\text { Do you believe that your } \\
\text { mother/father is good at } \\
\text { mathematics? What makes you } \\
\text { believe that? }\end{array}$ \\
\hline \multicolumn{4}{|l|}{ Affect system } \\
\hline Attitudes (ATT) & $\begin{array}{l}\text { Do you like mathematics? } \\
\text { Why? }\end{array}$ & $\begin{array}{l}\text { Does your mother/father believe } \\
\text { that you like mathematics? What } \\
\text { makes you believe that? }\end{array}$ & $\begin{array}{l}\text { Do you believe that your mother/ } \\
\text { father like mathematics? What } \\
\text { makes you believe that? }\end{array}$ \\
\hline Values (VAL) & $\begin{array}{l}\text { Do you believe that } \\
\text { mathematics is important } \\
\text { and necessary for you? What } \\
\text { makes you believe that? }\end{array}$ & $\begin{array}{l}\text { Does your mother/father believe } \\
\text { that mathematics is important } \\
\text { and necessary for you? What } \\
\text { makes you believe that? }\end{array}$ & $\begin{array}{l}\text { Do you believe that mathematics } \\
\text { is important and necessary for } \\
\text { your mother/ father? What } \\
\text { makes you believe that? }\end{array}$ \\
\hline Nature (NAT) & $\begin{array}{l}\text { Do you believe that } \\
\text { mathematics is difficult for } \\
\text { you? What makes you believe } \\
\text { that? }\end{array}$ & $\begin{array}{l}\text { Does your mother/father believe } \\
\text { that mathematics is difficult for } \\
\text { you? What makes you believe } \\
\text { that? }\end{array}$ & $\begin{array}{l}\text { Do you believe that mathematics } \\
\text { is difficult for your mother/ } \\
\text { father? What makes you believe } \\
\text { that? }\end{array}$ \\
\hline$\overline{\text { Self-confidence (SEC) }}$ & $\begin{array}{l}\text { Do you want to solve difficult } \\
\text { problems in mathematics? } \\
\text { What makes you believe } \\
\text { that? }\end{array}$ & $\begin{array}{l}\text { Does your mother/father want } \\
\text { you to solve difficult problems in } \\
\text { mathematics? What makes you } \\
\text { believe that? }\end{array}$ & $\begin{array}{l}\text { Do you believe that your } \\
\text { mother/father want to solve } \\
\text { difficult problems in } \\
\text { mathematics? }\end{array}$ \\
\hline $\begin{array}{l}\text { Child-parent } \\
\text { collaboration for } \\
\text { homework (CPC) }\end{array}$ & $\begin{array}{l}\text { Do you believe that you need } \\
\text { help from your parents at } \\
\text { home in mathematics? What } \\
\text { makes you believe that? }\end{array}$ & $\begin{array}{l}\text { Does your mother/father believe } \\
\text { that you need her/his help at } \\
\text { home in mathematics? What } \\
\text { makes you believe that? }\end{array}$ & $\begin{array}{l}\text { Do you believe that your } \\
\text { mother'/father's help is what you } \\
\text { need at mathematics? What } \\
\text { makes you believe that? }\end{array}$ \\
\hline
\end{tabular}

Figure 1. The six axes of the tri-focussed conceptualisation of mathematical identity

attainment, b) a dynamic affect system including attitudes, beliefs about nature of mathematics, values and self-confidence, and c) child-parent collaboration for homework. Our research questions were formulated as follows: a) How do sixth graders position themselves and their parents on these axes of their identity? b) Upon which types of resources is their positioning based with respect to their parental involvement in mathematics?

\section{METHOD}

The reported case study was conducted in May 2015 with the students (15 students, 8 boys and 7 girls) attending the $6^{\text {th }}$ grade (12 years old) of a "mainly of dominant ethnicity" primary school (around $85 \%$ students of Greek origin) in Athens, Greece. The school was selected as representing the majority of the schools in Greece and hence as being typical of the interaction of the Greek school with the Greek family. The choice of students of the $6^{\text {th }}$ grade was based on the fact that it is the last grade of the primary school in Greece before high junior. Importantly for the purposes of this study, the students of this class attended the same primary school unit for all the six grades of primary school education. They experienced a common school environment for the six years of primary school, referring to the teachers, the school unit amenities and the broader school experiences. Thus, these allow for investigating the role of parental involvement as a factor that shapes the students' mathematical identity.

The collection of data based on structured interviews. The children were interviewed in their school by their teacher. Each interview was audio-recorded and lasted about 30 minutes. The interview was structured through a series of questions for each of the following axes (see Figure 1): attainment (ATN), attitudes (ATT), values (VAL), nature of mathematics (NAT), self-confidence (SEC) and child-parent collaboration for homework (CPC), in line with the tri-focused model of Abreu and Cline (2003).

The analysis of the results drew upon two directions: a) students' positioning and b) types of students' resources used for their positioning. The analysis contrasted two groups of students: those who identified themselves as being "good at maths" (Group A; $\mathrm{N}_{\mathrm{A}}=7$ ), and those who identified themselves as being "average at maths" (Group $\mathrm{B} ; \mathrm{N}_{\mathrm{B}}=8$ ). This contrast was expected to reveal qualitatively different positioning and resources concerning the localised aspects of their mathematics life.

Moreover, the students' types of resources were identified through an iterative, inductive process, which included independent analysis of all three members of the research team, until consensus was reached. First, each of the audio recordings was transcribed, then we began to establish categories based on similarities and 
Table 1. Students' positioning about attainment

\begin{tabular}{|c|c|c|c|c|c|c|}
\hline & & \multicolumn{2}{|c|}{ Being identified } & \multirow[t]{2}{*}{ Self-identification } & \multicolumn{2}{|c|}{ Identifying the other } \\
\hline & Attainment & Mother & Father & & Mother & Father \\
\hline \multirow{2}{*}{ Group A } & good & 7 & 5 & 7 & 5 & $5 *$ \\
\hline & average & & 1 & & 2 & 1 \\
\hline \multirow{3}{*}{ Group B } & good & 3 & 2 & & 5 & $7 *$ \\
\hline & average & 2 & 1 & 8 & 3 & \\
\hline & don't know & 3 & 4 & & & \\
\hline
\end{tabular}

Notes. *Two single-parent families were included in the study

differences about what was identified in each axis. In doing so, we tested the viability of our categories in the analysis process. Through this process, we identified types of resources which transcended all axes and specific resources, referring to the situated to each axis meanings that each type of resource obtained. Seven types of resources were identified: a) direct parental involvement, b) indirect parental involvement, c) school life, d) students' feelings, e) students' beliefs about mathematics education, f) social life, and g) parents' professional life and their mathematics' abilities. The resources are presented and analysed in the results section according the three identity foci: self-identification, being identified by their parents (mother/father) and identifying their parents (mother/father).

\section{RESULTS}

The presentation of the results is organised firstly on the students' positioning on relevant questions in the first five axes which were included in the interview. Subsequently, we present the students' resources used by them, which enabled us to identify similarities and differences concerning students' resources across the five axes. In the last section, the students' perceived parental collaboration at home (the $6^{\text {th }}$ axis) is presented, which essentially incorporates and clarifies the role of parents-students' interaction that we identified in their previous answers. Note that instead of students' names we use the following numbers $1,5,6,8,9,11,12$ for the students of Group A (accompanied with the letter A) and the following numbers 2,3,4,7,10,13,14,15 for the students of Group B (accompanied with the letter B). So, in the presentation of the results, we use the notation Student-Number-Group (for example, Stud1A is student 1 who is self-identified as being good at maths).

\section{The Students' Positioning}

In Table 1 we summarise the students' positioning about mathematics attainment through selfidentification, being identified by their parents and identifying their parents.

Concerning the students of Group A, five of them reported that both of their parents also identified them as 'good' at mathematics, whilst only one student stated that his father consider him as 'average': "[My father] doesn't believe that I'm good, he thinks I'm ok" (Stud9A). On the contrary, five of the students of Group B stated that they did not know about at least one of their parents' perception of their mathematics attainment. More specifically, two of the students reported both of their parents as 'don't know' (Stud2B, Stud4B), two reported only their father as 'don't know' (Stud10B, Stud15B), and one only her mother (Stud3B). Only one self-identified 'average' student (Stud7B) reported that both of their parents identified him as being 'good', whilst another reported that only his mother considered him as "good" and his father as 'average' (Stud13B). In both single-parent families, we found complete agreement between the daughters and their mothers. Consequently, though the 'good' students experienced a consistency in their positioning about mathematics attainment between self-identification and being identified by their parents, the 'average' students did not experience such a consistency (Kafoussi et al., 2017). Importantly, the 'average' students appeared to not know what their parents thought of their mathematics attainment.

Moreover, most of the students identified both of their parents as 'good' at mathematics. Nevertheless, it should be noted that the characterization 'average' predominantly referred to the mother and was a consequence of the students' spontaneously comparing the two parents. For example, "My father is definitely better ... because if I don't know something, I ask him, he answers. My mother does not may reply immediately" (Stud4B).

In Table 2 we summarise the students' positioning about the affective system concerning mathematics that we considered in the mathematics identity as conceptualised in this study, namely: attitudes, values, nature and self-confidence. 
Table 2. Students' positioning about attitudes, values, nature and self-confidence

\begin{tabular}{|c|c|c|c|c|c|c|c|c|c|c|c|c|c|c|c|c|c|c|c|c|c|}
\hline \multirow{3}{*}{ 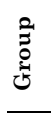 } & & \multicolumn{8}{|c|}{ Being identified } & \multicolumn{4}{|c|}{ Self-identification } & \multicolumn{8}{|c|}{ Identifying the other } \\
\hline & & \multicolumn{4}{|c|}{ Mother } & \multicolumn{4}{|c|}{ Father } & \multirow[b]{2}{*}{ ATT } & \multirow[b]{2}{*}{ VAL } & \multirow[b]{2}{*}{ NAT } & \multirow[b]{2}{*}{ SEC } & \multicolumn{4}{|c|}{ Mother } & \multicolumn{4}{|c|}{ Father } \\
\hline & & ATT & VAL & NAT & SEC & ATT & VAL & NAT & SEC & & & & & ATT & VAL & NAT & SEC & ATT & VAL & NAT & SEC \\
\hline & Yes & 6 & 7 & & 7 & 5 & 6 & 1 & 6 & 7 & 6 & & 6 & 5 & 6 & 1 & 4 & 4 & 5 & 1 & 3 \\
\hline A & Smt & & & 2 & & & & & & & & 1 & & & & & & & & & \\
\hline & No & 1 & & 5 & & 1 & & 5 & & & 1 & 6 & 1 & 2 & 1 & 6 & 3 & 2 & 1 & 5 & 3 \\
\hline & Dnk & & & & & & & & & & & & & & & & & & & & \\
\hline & Yes & 6 & 8 & 2 & 6 & 5 & 5 & 2 & 4 & 7 & 7 & & 4 & 5 & 8 & 4 & 5 & 7 & 7 & & 4 \\
\hline B & Smt & & & & & & & 2 & & & & 6 & & & & & & & & & 1 \\
\hline & No & 2 & & 6 & & 1 & 1 & 2 & 1 & 1 & 1 & 2 & 4 & 2 & & 4 & 3 & & & 7 & \\
\hline & Dnk & & & & 2 & 1 & 1 & 1 & 2 & & & & & 1 & & & & & & & 2 \\
\hline
\end{tabular}

Notes. Attitudes (ATT), Values (VAL), Nature of mathematics (NAT), Self-confidence (SEC).

'Yes': Yes, 'Smt': Sometimes, 'No': No, 'Dnk': Don't know.

Concerning the students' positioning about their attitudes for mathematics, both groups expressed mostly a positive attitude towards mathematics and there was an agreement on students' answers concerning how they were being identified by their parents. Only one student from Group B declared that she didn't like mathematics because "she was bored" (Stud3B). Moreover, most of the students of the two groups declared that their parents like mathematics. A few students that they answered negatively commented like following: "She doesn't deal with it. She avoids it" (Stud3B).

Both groups of students (except of two students) believed that mathematics is important in their lives and their parents mostly had the same opinion with them. One student from Group B said that her father believed that mathematics was not important for her as "I have discussed with them what job I want to do and I don't think that it needs mathematics, so he has concluded that I don't like mathematics and I will not need them in the future" (Stud2B) and another one said that she did not know (Stud4B) what her father believed. Moreover, the students commented positively about the importance of mathematics in their parents' lives.

However, there were more differences between the two groups about the difficulty of the subject, as the students of Group B believed that mathematics sometimes was difficult (six students). Moreover, the students of Group A reported that both of their parents identified them as not having difficulties with this subject and they believed the same for their parents' difficulty with mathematics. On the contrary, the students of Group B expressed different assessments about what their mothers and their fathers believed for them about their difficulty with this subject. More specifically, the students of Group B presented more positive assessments for themselves from their mother's part and a variety of assessments from their fathers' part (6 students answered "no" at this question for their mother but they gave all the answers, "yes", "no" or "sometimes" talking for their father).Consequently, as we have also commented about the students' positioning concerning their attainment, the 'average' students did not experience a consistency in their positioning about the nature of mathematics between self-identification and being identified by their parents. Furthermore, when the students of Group B were asked to identify their parents, half of them expressed the opinion that their mothers experienced difficulties with mathematics, but all of them believed that their fathers did not have any difficulties with this subject.

Finally, concerning the students' positioning about their self-confidence, the students of Group A expressed more positive disposal to solve difficult problems in mathematics compared to the students of Group B (half of them answered "no"). Moreover, the students of Group A were in accordance with the perceived being identified by their parents. On the contrary the students of Group B expressed again more positive assessments for themselves from their mother's part, whilst two of them stated that they did not know what their parents believed for them (Stud4B, Stud15B).

Furthermore, many students from Group A believed that their parents didn't want to solve difficult problems in mathematics because "they don't like to think". In contrast, many students of Group B said that their parents wanted to solve difficult problems in mathematics in order to "test" themselves if they could manage to find the solution.

In summary, the 'good' students experienced a consistency in their positioning about attitudes, values, nature and self-confidence between self-identification and being identified by their parents, since the 'average' students did not experience such a consistency especially about nature and self-confidence. 
Table 3. The students' resources about self-identification

\begin{tabular}{|c|c|c|c|c|c|c|}
\hline Types of Resources & Specific Resources & ATN & ATT & VAL & NAT & SEC \\
\hline \multirow{2}{*}{ a. School life } & Dealing with school tasks & 7 & 9 & & 5 & 8 \\
\hline & School performance & 1 & & & & \\
\hline b. Feelings & & 4 & 7 & & 5 & 8 \\
\hline \multirow{4}{*}{ c. Students' beliefs about } & Mathematics Learning & 6 & & & 9 & \\
\hline & Professional life & & & 9 & & \\
\hline & Future studies & & & 4 & & \\
\hline & Personality & & & 2 & & \\
\hline d. Social life & Activities & & & 8 & & \\
\hline
\end{tabular}

\section{The Students' Resources}

\section{Resources used in self-identification}

Considering the students' self-identification resources through the five axes, we identified four general types of them (summarised in Table 3): their experiences from their school life, their feelings about mathematics, their beliefs about issues concerned mathematics education as well as their social life. We should note that for each axis the students used the same resource although their expressions were different respectively to the question they answered.

One common type of resource for their self-identification for almost all the axes (except values) was their experiences from their school life and more specifically their dealing with school mathematical tasks. For example, the students linked their attainment with the mistakes made as they engaged to mathematics tasks, their difficulty of solving problems and the lack of mathematical understanding: "I believe that in general I don't have 'gaps' (referring to the mathematics knowledge), it is just that sometimes I make mistakes because I do not pay attention ... few are the problems that I cannot solve" (Stud9A, ATN); "In problems, I have difficulty in thinking solutions" (Stud3B, ATN); "I am not sure why sometimes also depending on the topic I may get confused, not understand well" (Stud7B, ATN). Only one student reported his official school performance (grades) as a resource for his attainment: "Because I have seen how well I go with mathematics at school from my grades" (Stud8A, ATN).

Moreover, when they talked about their attitudes, their dealing with school mathematical tasks was connected with the finding of different ways in solving mathematical problems: "You find a lot of ways in order to solve a problem, this is something special" (Stud5A, ATT) and the easiness or the difficulty of specific mathematical topics talking about the nature of mathematics: "Some mathematical issues are difficult" (Stud6A, NAT); "I have not understood what we are doing now with the squares, the alpha on the second (he means the area of a square)" (Stud7B, NAT). They connected their self-confidence with school life through their ability or not of solving a difficult problem as follows: "Yes, I want to solve a difficult problem in mathematics in order to think more and to see it from different views, if it does not come out to try otherwise" (Stud11A, SEC); "Yes, I want to solve difficult problems in mathematics in order to try where I can get to math" (Stud1A, SEC); "No, I don't want to solve difficult problems, because I could do mistakes" (Stud15B, SEC); "No, I am not good in thinking solutions" (Stud 3B, SEC); "No, I can't solve them" (Stud13B, SEC).

Concerning the second major type of resources that the students used for their positioning on their selfidentification, we included the students' feelings that were connected with the students' experiencing pleasure or ease of mathematics. For example, when they talked about their attainment: "I think that it [mathematics] is easier than the other courses" (Stud1A, ATN); "I have liked it [mathematics] since little girl" (Stud6A, ATN); "Because my favourite subject is mathematics and I only work with that" (Stud5A, ATN) or their attitudes "It is more pleasant than the other lessons" (Stud1A, ATT); "I borrow with them" (Stud3B, ATT) or the nature of mathematics "It is like a natural game" (Stud8A, NAT); "I like operations" (Stud12A, NAT); "I don't have to write words like in literature" (Stud9A, NAT). Finally, when they reported on their self-confidence, they justified their answers as follows: "No, because if I could not manage to solve it I would feel a little awful" (Stud6A, SEC); "No, because you have to think more and I'm tired" (Stud2B, SEC); "Because I like to think" (Stud10B, SEC).

The third students' type of resource was the students' beliefs about different aspects of mathematics education. They characterized their self-identification as "good" or "average" in mathematics based on their beliefs about the practices that a student should follow in order to be successful in learning mathematics, like the time spent studying the specific course at home or the lack of attention: "Because sometimes I study and sometimes I don't study much" (Stud7B, ATN); "I devote time to mathematics, I sit down many hours and 
Table 4. The students' resources about being identified by their parents

\begin{tabular}{|c|c|c|c|c|c|c|}
\hline Types of Resources & Specific Resources & ATN & ATT & VAL & NAT & SEC \\
\hline \multirow{2}{*}{ a. Direct parental involvement } & Interaction or not with parents at home & 13 & & 1 & 5 & 1 \\
\hline & Parents' observations on their children's practices & 3 & 10 & & 1 & 1 \\
\hline \multirow{5}{*}{ b. Indirect parental involvement } & Parents' expectations & 4 & 4 & & 5 & 2 \\
\hline & Parents' beliefs about mathematical learning & & & & 7 & 10 \\
\hline & Parents' beliefs about professional life & & & 8 & & 1 \\
\hline & Parents' beliefs about the role of math education & & & 5 & & \\
\hline & Parents' beliefs about math tasks & & & & 4 & \\
\hline c. Social life & Daily activities & & 1 & 7 & & \\
\hline d. School life & Teacher's assessment & 3 & 3 & & & 1 \\
\hline
\end{tabular}

study" (Stud1A, ATN); "I don't remember well theories, that is I cannot remember staff that we were told three years ago and I may mistake one for another sometimes" (Stud2B, ATN); "Many times in class I don't pay attention... and sometimes I am not focused in at home" (Stud14B, ATN). The same arguments were used when they talked about the nature of mathematics: "It depends, if I pay attention" (stud6A, NAT); "It is not difficult if you read it" (Stud10B, NAT); "If I concentrate and I pay attention on the board, it's ok" (Stud13B, NAT).

Moreover, they referred to their beliefs about the role of mathematics in their future professional life, their future studies and their personality as well as their social life in order to provide arguments about how they perceived the value of mathematics: "Mathematics are useful whatever you become ... even a simple treasurer" (Stud1A, VAL); "You need to learn them in order to find a job" (Stud2B, VAL); "Because later on in high school I will study mathematics" (Stud3B, VAL); "Mathematics put you in a process of thinking and so as you grow up and you are good, you will think a little more" (Stud10B, VAL); "When you want to buy something in a store" (Stud5A, VAL); "Because If I go to a country where I don't know the language, for example in Spain. Maybe I will not understand what they say but I can pay I will see the bill” (Stud15B, VAL).

It should be stressed that both group of students reported all the types of resources. However, we should note that the students of Group A talked more than the students of Group B for their positive feelings about mathematics, whilst the 'average' students perceived themselves mainly through their (in)ability to cope with the school tasks or through their lack of studying at home and their lack of paying attention. Furthermore, according to the above results, the students mainly shape their personal relationship with mathematics (attainment, attitude, nature, self-confidence) through their ability or not in school mathematical tasks, their feelings and their beliefs about the learning of mathematics. The value of this subject is mainly connected to their future professional life but also with activities in their daily life.

\section{Resources used in being identified by their parents}

We distinguished four types of general resources that informed the students in order to explain why their parents expressed a positive or negative opinion for them through the different axes of their mathematical identity: direct parental involvement, indirect parental involvement (parents' beliefs and expectations), social life and school life (see Table 4). More specifically, when the children talked about why they were identified by their parents in a concrete manner, they were based on their interaction with them (direct parental involvement) and their parents' expectations (indirect parental involvement) for almost all the axes. Indirect parental involvement connecting with their parents' beliefs was also mentioned when they discussed about values, nature or their self-confidence in mathematics.

The direct child-parent involvement was mainly connected with the parents' checking of mathematical activities at home or the parents' observations of their children's work at home (especially considering the students' constructing of their parents' perception about attitudes). For the 'good' students this interaction had a positive orientation: "Yes, she gives me exercises [to solve] and checks how well I do, I do it quickly, correctly" (Stud1A, ATN); "Because when she sees me doing mathematics at home with the exercises, she sees that 'I've got it' [meaning he is good] with mathematics" (Stud11A, ATN); "Because she sees me when sometimes I stick to my mind and she helps me" (Stud12A, NAT); "On summers and in general on holidays generally, he wants continuously to make repetitions in mathematics" (Stud6A, VAL); "In order to see my progress, how I manage to deal with difficult problems" (Stud8A, SEC); "Because sometimes she gives me difficult problems even when I help her at her bookstore" (Stud12A, SEC). On the contrary, for the 'average' students this interaction had either negative attributes or it was missing: "Because I don't study with her mathematics and she doesn't know" (Stud3B, ATN); "I don't know ... because my mother has brought a person 
named George to tutor me" (Stud4B, ATN); "Because he tells me to solve exercises and I tell him that I am borrowing" (Stud3B, ATT); "When she asks me sometimes if I need something in mathematics, I have already do it and I don't need help" (Stud3B, NAT).

The second type of resource (indirect parental involvement) was connected with parental expectations for almost all the axes. These expectations were linked with the trust of the parents towards their child. Illustrative examples from their answers were the following: "Because, she believes in me that I can do more in mathematics" (Stud5A, ATN); "She believes that I can do it and even if I don't ask for her help (Stud9A, ATN); "Yes, because she's also good and she sort of knows what I can do and she compares with her own [mathematics knowledge] and she thinks that I am good" (stud12A, ATN); "Because I have told her and she believes me" (stud14B, ATT); "He is sure that I can do it myself" (Stud7B, NAT); "He is good at mathematics due to his job and he believes that I also easily catch them" (Stud10B, NAT); "He believes that I can solve difficult problems" (Stud1A, SEC); "No, he believes that I may not understand the pronunciation and I will do a lot of time to solve it. He asks me to solve easier problems" (Stud2B, SEC).

Moreover, the second type of resource (indirect parental involvement) for many students was connected with their parents' beliefs about mathematical learning when they talked about how their parents identified them concerning their difficulties with mathematics (nature) and their self-confidence: "He believes that mathematics is a little difficult for me, as when I read it I don't concentrate" (stud6A, NAT); "No, she believes that mathematics needs more reading than other subjects" (stud10B, NAT); "No, she believes that if I concentrate, I will manage it" (stud14B, NAT); "Yes, she says that I will understand more in this way" (Stud2B, SEC).

They also connected this type of resource with their parents' beliefs about the role of mathematics in their future professional life, when they commented about how their parents perceived if mathematics were important for them (value): "She says to my sister that even if you go to paramedics (professions), you need math"(Stud1A, VAL); "Because he knows that I want to be an architecture and I need math"(Stud9A, VAL); "In order to have a good job (for both parents)" (Stud8A, VAL); "Let's say if you want to be a footballer you have to know how much power you put in, my dad ... he told me that for all the goals he scored, he used math" (Stud13B,VAL) or to their parents' beliefs about the role of math education: "They say all my life I have to do with math ... and until I finish school" (Stud3B, VAL); "Because he says that if I do not know math I will not be the right person" (Stud6A, VAL); "She says that if you are good at math, you will not be only good at numbers, you will be generally good to think and to be wise with things" (Stud10B, VAL). Four children related indirect parental involvement with their parents' beliefs about the difficulty of concrete mathematical tasks in school talking about nature: "This year with equations and proportions she believes it is difficult, but not for me because I manage them" (Stud8A, NAT).

Concerning the third type of resource (social life), some children referred to their social activities in order to explain how they were identified by their parents: "Because I learn chess that wants a lot of thought and I love it, I like to think, so which lesson has a lot of thought? Mathematics!" (Stud10B, ATT); "Yeah, because if I go out in the world and I want to go to the supermarket, if I do not know math I will not know how much to change" (Stud12A, VAL); "Because sometimes they help ... how you manage the money you have earned" (Stud2B, VAL).

Finally and notably, school life does not seem to constitute an important type of resource for the formation of their parents' perceptions according to the children. A few children referred to it: "Because she has seen the mathematics grades of the two trimesters" (Stud8A, ATN); "I don't read with her at home, so from the report card and only (from this)" (Stud3B, ATN).

According to our results, both group of students used all the types of the mentioned resources above. They mainly shaped their positions about how they are being identified by their parents based on their direct interaction with them at home as well as on their perceived expectations (see attainment, attitude, nature, self-confidence). The "good" students had a smooth communication with their parents at home as they engaged in their school tasks and they trusted each other about their abilities. Another resource that influenced the students' mathematical identity formation was their parents' beliefs about the learning of mathematics, where we can observe that the perceived parents' beliefs were analogous to the students' beliefs about mathematical learning as they were expressed for their self-identification. Moreover, as we have already mentioned in the previous section, the value of the subject was mainly connected to their future professional life and with activities in their daily life. Furthermore, we found out that the Group A's and Group B's students did not differentiate their resources according to their reference to their mother or father. 
Table 5. The students' resources about identifying their parents

\begin{tabular}{|c|c|c|c|c|c|c|}
\hline Types of Resources & Specific Resources & ATN & ATT & VAL & NAT & SEC \\
\hline a. Direct parental involvement & Interaction or not with parents at home & 11 & 9 & 2 & 6 & \\
\hline \multirow{2}{*}{ b. Indirect parental involvement } & Parents' positioning & 6 & 6 & 2 & 8 & \\
\hline & Parents' attitudes & & & & & 14 \\
\hline c. Professional life & Parents' profession & 6 & 7 & 12 & 5 & 2 \\
\hline d. Knowledge & Parents' abilities & & & & 4 & 7 \\
\hline e. Social life & Parents' daily activities & 1 & 1 & 5 & 3 & 2 \\
\hline
\end{tabular}

\section{Resources used in identifying the other (mother and father)}

We distinguished five types of resources that the students used in order to identify their parents' relationship with mathematics: direct parental involvement, indirect parental involvement (parents' positioning and attitudes), parents' professional life, parents' knowledge and social life (see Table 5). These types of resources connected with all the axes, although there were some qualitatively different characteristics about these resources comparing how they were used for the being identified by their parents.

Concerning direct parental involvement, the justifications that the children gave in order to characterize the relationship of their parents with math revealed that the assessment about the quality of parental help at home was a main resource. For example, the students said: "She explains it, whatever I haven't understood is like having a lesson ...yes I understand it well" (Stud1A, ATN); "He showed me an easy way to do divisions without having difficulties" (Stud5A, ATN); "When I ask him to help me with the exercises, he talks about other issues to get away with it" (Stud8A, ATN); "When we talk about mathematics, she talks about it with great ease" (Stud11A, NAT).

Moreover, the second type of resource (indirect parental involvement) was connected with their parents' declared positioning about their own mathematical performance or about their own positive or negative attitudes through their discussions with their children at home. For example: "Every time I ask for her help she tells 'look 'I don't have it' that much with math" (Stud9A, ATN); "He/she told me that" (Stud13B, ATT; Stud8A, NAT); "Yes it is difficult, because sometimes I ask her and she told me that it has been a long time"(Stud15B, NAT); "He likes more to solve the difficult problems" (Stud11A, ATT; Stud4B, SEC; Stud14B, SEC); "I don't think that he/she likes it" (Stud1A, SEC; Stud9A, SEC); "He avoids them" (Stud5A, SEC); "The adults do not like to think" (Stud11A, SEC); "She doesn't want to do math" (Stud10B, SEC).

The third major type of resource that the students used in order to characterize their parents' positive relationship with mathematics in all the axes was their professional life. Many students answered as follows: "My father-because of his profession- I believe that he is good. He uses measurements every day, he remembers it in general. Ok in mathematics he is good" (Stud9A, ATN); "He needs math in his work" (Stud6A, ATT; Stud2B, VAL; Stud7B, V; Stud13B, SEC); "I see him doing operations in the pavilion" (Stud15B, NAT); "He is a taxi driver and needs it (maths)" (Stud1A, VAL).

Finally, some students referred to their parents' knowledge: "She doesn't make mistakes" (Stud5A, NAT); "She is clever and she can do it with her mind" (Stud6A, NAT); "I see her that she can solve difficult problems" (Stud12A, SEC); "He is good in math" (Stud7B, SEC); "She is not very good, she doesn't want to solve difficult problems" (Stud7B, SEC). Others referred to their parents' social life through their daily practices in order to justify their parents' relationship with mathematics: "She is also a manager and she does all the operations" (Stud1A, ATT); "Because she maybe need them in the daily life" (Stud11A, VAL); "She solves some puzzles in magazines" (Stud13B, SEC).

Both group of students used all the types of the mentioned resources above. They mainly shaped their positions about the identification of their parents based on their direct interaction with them through the quality of their help in mathematics homework as well as on their parents' declared positioning about their own mathematical performance or attitudes through their discussions at home. The value of the subject for their parents is mainly connected to their professional life. However, we should note that the parents' profession appears to be a more dominant type of resource in Group B, especially for their father, something that it could be interpreted as their own outlet, since these students have declared that they didn't interact directly with their parents at home. On the contrary, concerning the identification of their mother, both groups based more on the indirect parental involvement and especially their discussions with their mother (mother's positioning) in order to characterize her relationship with math for all the axes. 
Table 6. Students' positioning about the need for their parents' collaboration at home

\begin{tabular}{|c|c|c|c|c|c|c|}
\hline & \multirow{2}{*}{ Child-parent collaboration } & \multicolumn{2}{|c|}{ Being identified } & \multirow{2}{*}{ Self-identification } & \multicolumn{2}{|c|}{ Identifying the other } \\
\hline & & Mother & Father & & Mother & Father \\
\hline \multirow{3}{*}{ Group A } & Yes & 0 & $2^{*}$ & 3 & 4 & $4^{* *}$ \\
\hline & Sometimes & 2 & 3 & 1 & 1 & \\
\hline & No & 5 & 1 & 3 & 2 & 1 \\
\hline \multirow{3}{*}{ Group B } & Yes & 5 & 2 & 1 & 6 & $6^{* *}$ \\
\hline & Sometimes & 0 & & 6 & 1 & \\
\hline & $\mathrm{No}$ & 3 & 5 & 1 & 1 & \\
\hline
\end{tabular}

Notes. ${ }^{*}$ Two single-parent families were included in the study. ${ }^{* *}$ one student didn't answer.

\section{Child-parent Collaboration for Homework}

The students' positioning about their need for collaborating with their parents at home in mathematics is summarised in Table 6.

The majority of the students and especially the students of Group B declared that they need their parents' collaboration in their homework at mathematics. However, there were differences between the two groups about how the students were being identified by their parents. The students of Group A believed that according to their mothers they don't need help, but according to their fathers they need help about mathematics at home. In contrast, the "average" students believed that according to their mothers they need help, but according to their fathers they don't need help. According to our results, the students of group A seem to agree mostly with their fathers and the students of group B with their mothers. This finding is interesting as we have found that the perceived parental involvement qualitatively differs between the mother and the father about mathematics, as the children's perception of their father's role is connected with a wider range of mathematical practices (including checking homework frequently, asking about assessment results, encouragement) (Moutsios-Rentzos et al., 2015). Furthermore, the majority of the students seemed to appreciate the effectiveness of their mothers' and fathers' help.

The students' resources which they resorted in order to position themselves about the need of help from their parents at home in mathematics for both groups were their self-identification about their ability: "No, because I understand it [mathematics], I don't have any problem" (Stud1A, ATN); "Yes, because I believe that I am an average student" (Stud7B, ATN). Others reported their difficulty in dealing with school tasks or their beliefs about mathematical learning: "When I have difficulties with something" (Stud5A, ATN); "It depends on the topic that we have to solve, for example if it concerns equations" (Stud2B, ATN); "Sometimes I miss some things from the blackboard and I don't remember them" (Stud13B, ATN); "Yes, I don't pay a lot of attention" (Stud6A, ATN).

Concerning the types of resources used about their being identified by their parents, the students were based on their parents' expectations: "I have shown her that I can solve it alone "(Stud6A); "No, he [father] believes that I can solve them [problems]on my own, if I concentrate" (Stud2B), direct parental involvement: "Yes, she gives me exercises and she sees that I need help" (Stud14B), parents' abilities: "My mum doesn't know a lot about math" (Stud7B) as well as their difficulties dealing with school tasks (school life): "Sometimes I can't solve concrete exercises" (Stud6A).

Finally, the students were based only on the direct parental involvement in order to justify the efficacy of their parents' help. Although the students declared satisfied from their parents' help, mainly due to their explanations when they didn't understand a mathematical issue, there were qualitative differences between the comments of the two groups. That is, for the Group A direct parental involvement was connected only with positive experiences: "Yes, because my mum understands me better and she explains it in a better and funny way" (Stud6A); "We solve the problem together (he means with his father)" (Stud11A); "When I don't understand a problem, he explains it to me and I solve it" (Stud12A). However, the students of Group B expressed conflicting opinions about their parents' help: "No, because if I do a mistake, she tells me that it's wrong and write it like that" (Stud15B); "Sometimes yes, if I explain to her what we said in the lesson, her help is good. But sometimes that I need a little help, she puts other exercises, and other exercises ... and I become nervous" (Stud14B); "When I stick to my mind, she says that when she was a student she also stuck and she encourages me" (Stud13B).

Moreover, some students related the efficacy of their parents' help with the mathematics course to their school life: "She showed me another way of calculating the greatest common measure and I confused" (Stud1A), "Yes, because I can say the lesson that she told me in the classroom" (Stud5A). 
Concerning mother's and father's help at home, five students spontaneously compared their mothers' and fathers' practices like follows: "She explains it to me with more simple words ...my father makes it more complicated and I don't understand" (Stud6A); "He explains it to me a little better than my mum" (Stud9A); "My dad has almost the same practice with my mum. He will help me, he will explain it to me again and again if I don't understand." (Stud7B).

\section{DISCUSSION AND CONCLUDING REMARKS}

In this study, we investigated the parental influences on the construction of students' mathematical identity in a primary school in Greece. We focused on how sixth graders position themselves and their parents and what types of resources they use in order to explain their positioning concerning their parents' involvement in their mathematics life in the three aspects of identity: self-identification, being identified and identifying the other (Abreu \& Cline, 2003). Our approach was based on six axes: a) mathematics attainment, b) a dynamic affect system including attitudes, beliefs about the nature of mathematics, values and selfconfidence, and c) child-parent collaboration for homework. We conducted our investigations including the differentiation between father and mother, as supported by the family structure and function in Greece and the related research findings (Moutsios-Rentzos et al., 2015). We posited that these findings would help us to clarify what aspects of parental involvement are crucial for the construction of the children's identity in mathematics in order to discuss ways of supporting them.

According to our results about the students' positioning, we contrasted two groups of students: those who identified themselves as being "good at maths" and those who identified themselves as being "average at maths". The self-identified as 'good' students experienced a consistency in their positioning about mathematics attainment between self-identification and being identified by their parents, but the self-identified as 'average' students did not experience such a consistency. Concerning the students' positioning about the affective system of mathematics that we considered in this study (attitudes, values, nature and self-confidence), we found that both groups expressed mostly positive attitudes towards mathematics through the three aspects of identity (self-identification, being identified and identifying the other). Moreover, the students' answers about the importance of mathematics on their own and their parents' lives seemed to confirm the social value of mathematics (Keitel \& Vithal, 2008). However, there were more differences between the two groups about the nature of the subject and their self-confidence. According to our findings, the 'good' students reported that both of their parents identified them as not having difficulties with this subject and they believed the same for their parents' difficulty with mathematics. Moreover, they expressed positive disposition to solve difficult problems in mathematics and they were in accordance with the perceived being identified by their parents. On the contrary, the 'average' students presented more positive assessments for themselves from their mother's part and a variety of assessments from their fathers' part with respect to their difficulty with mathematics and self-confidence and they evaluated differently their mothers from their fathers (they reported that their mothers experienced more difficulties with mathematics).

Considering the students' self-identification resources, we identified four types: a) experiences from their school life, b) feelings about mathematics, c) beliefs about issues concerned mathematics education, and d) social life. The students mostly based their self-identification in mathematics on their negative or positive experiences from their school life (which they were connected with their success (or not) to solve the mathematical problems in which they engaged), their feelings about the subject, the time spent studying the specific course at home or to the lack of attention at home or at school and the usefulness of mathematics in their future professional life or their current social life.

Furthermore, regarding being identified by their parents, we distinguished four types of resources that the students used in order to inform themselves why their parents expressed a positive or negative opinion for them through the different axes of their mathematical identity: a) direct parental involvement, b) indirect parental involvement (parents' beliefs and expectations), c) social life, and d) school life. More specifically:

-Direct child-parent involvement was mainly connected with the parents' checking of mathematical activities or the parents' observations of their children's work at home and this interaction had positive characteristics for the 'good' students, whilst for the 'average' students had either negative attributes or it was missing. Indirect parental involvement included their parents' expectations and beliefs about math.

-The parents' expectations seemed to play a major role concerning students' construction of identity, as they were linked with the trust of the parents towards their child in doing successfully math tasks, confirming other research results (Jacobs \& Bleeker, 2004; Wang, 2004). 
-The parents' beliefs concerned mathematical learning, professional life and the role of mathematics education. The parents' beliefs about mathematical learning were mostly connected with their child's study at home and the lack of attention at home or at school. There was an agreement between the factors that the students and their parents used in order to characterize the children's relationship with math through the way of their learning as both groups seem to use rather traditional beliefs about math education.

-The students' reports about professional or social life may be linked with the foreground of the students (Skovsmose, 2005) and they played a crucial role when the children tried to explain how they were being identified by their parents. The students were based on the parents' beliefs about their future professional life in order to answer about the value of mathematics when they talked about how their parents perceived if mathematics was important for them.

Finally, the students used five types of resources to identify their parents' relationship with mathematics: a) direct parental involvement, b) indirect parental involvement (parents' positioning and attitudes), c) parents' professional life, d) parents' abilities, and e) social life. The children's evaluations drew upon the quality of parental help at home to talk about the identification of their parents' relationship with math and upon their parents' declared positioning about their own mathematical performance or about their own attitudes (positive or negative) through their discussions with them at home. Their parents' professional or social life was also used by the students in order to justify their parents' relationship with mathematics. The fathers' profession was found to be particularly important for the 'average' students for the identification of their parents' relationship with math.

The above results showed that the parental influences on the construction of the students' mathematical identity at home are interwoven with their interaction with their parents. Based on Martin's (2007) conceptualization of mathematical identity, we could mention that the students expressed positive dispositions and beliefs about their ability to participate and perform effectively in mathematical tasks, when they collaborated with their parents at home in an environment of confidence. In the cases that this interaction was found to be missing, the students would experience less confidence to their abilities to deal with math tasks. In that occasion, they described their perceived parents' identification according to their parents' professional or social life.

Moreover, although the students mostly based their self-identification in mathematics on their negative or positive experiences from their school life, they didn't present a strong link between their being identified by the school and by the parents. That is, the students did not use the official or unofficial teachers' assessment or his/her discussions with their parents that exist in the Greek school system, in order to characterize how their parents identified them. They were based almost exclusively on their direct or indirect parental involvement with math. This is an important finding with respect to the students' affective relationship with mathematics, as it is well documented that the outcome of an educational system is closely related with its assessment system (Boud \& Falchikov, 2007). Further research may be conducted to delineate the nature and development of these links, as students progress through primary school to high-school.

Concerning their mother's and their father's involvement with mathematics at home, we found that the students held subtle, yet qualitatively different perceptions about them. They seemed to have a more positive evaluation about their fathers' abilities in doing math, as the students were usually spontaneously comparing the two parents; in particular, the mother's inability was signified through its being comparatively inferior to the father's ability. Although they used the same types of resources for both, it seemed that the mothers discussed more with their children at home, as both groups of students were based more on their discussions with their mother in order to characterize her relationship with math for all the axes. On the other hand, they were based more on their father's profession in order to answer the questions concerning his relationship about math.

Investigating children-parent collaboration for homework, the students declared that they needed their parents' collaboration in their homework at mathematics and they were based on the direct parental involvement in order to justify the efficiency of their parents' help. In general, the 'good' students considered that their collaboration with their parents was positive, whilst the 'average' students expressed conflicting points of view about it. This finding also confirms research results about the quality of the collaboration between parents and students that crucially determines the effectiveness of parental involvement on the students' preparing their homework (Hyde et al., 2006; Pezdek et al., 2002) and as a consequence influences students' disposition towards mathematics. 
In general, our results confirm previous research about the significant role of direct and indirect involvement in students' formation of their math identity (Cao, Bishop, \& Forgasz, 2006). At the same time, our findings complement the existing literature about parental influences on their children construction of their mathematical identity. In particular, we found that the perceived parents' beliefs about their children's future professional life as well as their actual parents' professions was another significant type of resource that the students used and it seemed to play a crucial role in their perceived relationship with math at home.

At this point, we should note that, in this case study, we investigated the students' perceptions of a sixth grade classroom in a "mainly of dominant ethnicity" school in Greece and not a multicultural one (respectively, around 85\% students of Greek origin, and various ethnicities were identified, with no ethnic origin exceeding $50 \%$ of the population; Moutsios-Rentzos et al., 2015). Thus, more research is needed with a larger sample of students and in relation to the cultural identity of the school they attend. We argue that such a line of research may be extended at cross-national level, to investigate the role of parents in different educational and sociocultural contexts (including, the broad environment, and the specific characteristics of the school unit and the family type).

Consequently, we posit that as daily work at home is a dominant cultural feature of the Greek educational system, parental practices in which children actively participate or interact indirectly offer different opportunities in shaping their mathematical identity. According to previous research results in our country the parents are led to shape traditional points of view about school mathematics education through their children's homework (Kafoussi et al., 2019). As the parents' collaboration with their children has been found to be crucial in their mathematical identity formation, it is hypothesized that students' homework may constitute a fruitful tool to be utilised within appropriately designed educational planifications, towards the reform of mathematics education (for example, by being based on recent recommendations about mathematics education and taking into account the characteristics of students' socio-cultural contexts, NCTM, 2000). The students' homework activities could help to reshape the parental engagement, as well as to re-define the school-family relationship about the teaching and learning of mathematics. Helping children to make connections between school, home and social life about what it means to do mathematics could help them to develop positive affective relationships with mathematics.

Following these, it is argued that the teachers' training should acknowledge and incorporate in the everyday teaching practices the importance of the teachers-parents immediate and mediated communication about mathematics. According to our research, the children's mathematical identity is crucially affected by both their interaction with their parents at home and their mathematical experience at school. Thus, we claim that when the teachers view their students as cultural beings with particular characteristics in their interaction with their parents, they would be open to position the parents as collaborators in mathematics teaching and learning. Extending this, it is noted that the design of teaching mathematics has to exploit or to better embed significant resources used by the students, which would help in their forming more productive mathematical identities. That is, as the findings of this study highlight that the parents' professional life and their social activities are crucial for the students' perceived parental interaction at home, the teachers could design mathematical activities that incorporate issues in relation to the professions and the social life of their students' parents. In our opinion this suggestion is in accordance with recent recommendations of mathematics educators about the connection between children's experiences from the real world and their mathematical learning (Van den Heuvel-Panhuizen, 2003). However, until now there has been limited focus on how parents might collaborate with educators to build more empowered mathematics identities for their children across students' home and school learning contexts (Ishimaru, Barajas- Lopez, \& Bang, 2015). The findings of this study support that appropriate planifications that would consider close, multi-leveled links between the family and the school unit may be designed towards fostering the students developing more fruitful, both for the educational and the broader social systems, mathematics identities.

\section{Disclosure statement}

No potential conflict of interest was reported by the authors. 


\section{Notes on contributors}

Sonia Kafoussi - University of the Aegean, Greece.

Petros Chaviaris - University of the Aegean, Greece.

Andreas Moutsios-Rentzos - University of the Aegean, Greece.

\section{REFERENCES}

Abreu, G. de (1995). Understanding how children experience the relationship between home and school mathematics. Mind, Culture and Activity, 2(2), 119-142. https://doi.org/10.1080/10749039509524693

Abreu, G. de, \& Cline, T. (2003). Schooled mathematics and cultural knowledge. Pedagogy, Culture and Society, 11(1), 11-30. https://doi.org/10.1080/14681360300200158

Abreu, G. de, Cline, T., \& Shamsi, T. (2002). Exploring ways parents participate in their children's school mathematical learning: Cases studies in multiethnic primary schools. In G. de Abreu, A. Bishop \& N. Presmeg (Eds.), Transitions between contexts of mathematical practices (pp. 123-147). Boston, MA: Kluwer. https://doi.org/10.1007/0-306-47674-6_6

Abreu, G. de, Gorgorio, N., \& Boistrup, L. B. (2018). Diversity in mathematics education. In T. Dreyfus, M. Artigue, D. Potari, S. Prediger, \& K. Ruthven (2018). Developing Research in Mathematics Education: Twenty years of communication in Europe (pp. 211-222). Oxon, UK: Routledge.

Anderson, A. (1997). Families and Mathematics: a study of parent- child interactions. Journal for Research in Mathematics Education, 28(4), 484-511. https://doi.org/10.2307/749684

Boud, D., \& Falchikov, N. (2007). Rethinking assessment in higher education learning for the longer term. London: Routledge. https://doi.org/10.4324/9780203964309

Bratton, J., Civil, M., \& Quintos, B. (2006). Engaging with parents on a critical dialogue about mathematical education. In M. Bosch (Ed.), Proceedings of the Fourth Congress of the European Society for Research in Mathematics Education (pp. 1182-1192). Sant Feliu de Guíxols, Spain: FUNDEMI IQS - Universitat Ramon Llull and ERME.

Cai, J., Moyer, J.C. \& Wang, N. (1997, March). Parental Roles in Students' Learning of Mathematics: An Exploratory Study. Paper presented at the annual meeting of the American Educational Research Association, Chicago, USA. Retrieved from ERIC database. (ED 412187)

Cao, Z., Bishop, A., \& Forgasz, H. (2006). Perceived parental influence on mathematics learning: a comparison among students in China and Australia. Educational Studies in Mathematics, 64(1), 85-106. https://doi.org/10.1007/s10649-006-9033-5

Crafter, S. (2012). Parental cultural models and resources for understanding mathematical achievement in culturally diverse school settings. Educational Studies in Mathematics, 81(1), 31-46. https://doi.org/10.1007/s10649-011-9359-5

Crafter, S., \& Abreu, G. de (2010). Constructing identities in multicultural learning contexts. Mind, Culture and Activity, 17(2), 102-118. https://doi.org/10.1080/10749030802707895

Darragh, L. (2016). Identity research in mathematics education. Educational Studies in Mathematics, 93(1), 19-33. https://doi.org/10.1007/s10649-016-9696-5

Galindo, C., \& Sheldon, S. (2012). School and home connections and children's kindergarten achievement gains: The mediating role of family involvement. Early Childhood Research Quarterly, 27(1), 90-103. https://doi.org/10.1016/j.ecresq.2011.05.004

Graven, M., \& Metzuyanim, E. (2019). Mathematics identity research: the state of the art and future directions. Review and introduction to ZDM Special Issue on Identity in Mathematics Education. ZDM, 51(3), 361-377. https://doi.org/10.1007/s11858-019-01050-y

Hepworth-Berger, E. (2004). Parents as partners in education. NJ, USA: Pearson Prentice Hall.

Hodge, L., \& Cobb, P. (2018). Two views of culture and their implications for mathematics teaching and learning. Urban Education, 1-25.

Hyde, J. S., Else-Quest, N. M., Alibali, M. W., Knuth, E., \& Romberg, T. (2006). Mathematics in the home: Homework practices and mother-child interactions doing mathematics. Journal of Mathematical Behavior, 25(2), 136-152. https://doi.org/10.1016/j.jmathb.2006.02.003 
Ishimaru, A., Barajas-Lopez, F. \& Bang, M. (2015). Centering family knowledge to develop children's empowered mathematics identities. Journal of Family Diversity in Education, 1(4), 1-21.

Jacobs, J. E. \& Bleeker, M. (2004). Girls' and boys' developing interests in Math and Science: do parents matter? New Directions for Child and Adolescent Development, 106, 5-21. https://oi.org/10.1002/cd.113

Kafoussi, S. (2006). Parents' and students' interaction in mathematics: designing home mathematical activities. Proceedings of CIEAEM 58, Quaderni di Ricerca in Didattica (Mathematics), 19(3), 79-85.

Kafoussi, S., Moutsios-Rentzos, A., \& Chaviaris, P. (2017). Investigating parental influences on sixth graders' mathematical identity: the case of attainment. In A. Chronaki (Ed.), Proceedings of the $9^{\text {th }}$ International Mathematics Education and Society Conference (MES 9), vol. 2, 592-602. Volos, Greece: University of Thessaly Press.

Kafoussi, S., Moutsios-Rentzos, A., \& Chaviaris, P. (2019). Constructing students' mathematical identity at home: the case of homework. Proceedings of CIEAEM 71 (in press).

Keitel, C., \& Vithal, R. (2008). Mathematical power as political power-the politics of mathematics education. In P. Clarkson, N. Presmeg (Eds.), Critical Issues in Mathematics Education, (167-186). Springer Science+Business Media, LLC. https://doi.org/10.1007/978-0-387-09673-5_12

Knapp, A., Landers, R., Liang, S., \& Jefferson, V. (2017). We all as a family are graduating tonight: a case for mathematical knowledge for parental involvement. Educational Studies in Mathematics, 95(1), 79-95. https://doi.org/10.1007/s10649-016-9741-4

Lange, T., \& Meaney, T. (2011). I actually started to scream: emotional and mathematical trauma from doing school mathematics homework. Educational Studies in Mathematics, 77(1), 35-51. https://doi.org/10.1007/s10649-011-9298-1

Martin, D. B. (2007). Mathematics learning and participation in the African American context: The coconstruction of identity in two intersecting realms of experience. In N. S. Nasir \& P. Cobb (Eds.), Improving access to mathematics: Diversity and equity in the classroom (pp. 146-158). New York: Teachers College Press.

Moutsios-Rentzos, A., Chaviaris, P., \& Kafoussi, S. (2015). School socio-cultural identity and perceived parental involvement about mathematics learning in Greece. Journal of Research in Mathematics Education, 4(3), 234-259.

Moutsios-Rentzos, A., \& Leontiou, E. (2016). Systemic investigations about parental involvement in mathematics. In B. Maj-Tatsis, M. Pytlak, \& E. Swoboda (Eds.). Inquiry based mathematical education (pp. 207-217). Rzeszow, Poland: Wydawnictwo Uniwersytetu Rzeszowskiego.

Mylonas, K., Gari, A., Giotsa, A., Pavlopoulos, V., \& Panagiotopoulou, P. (2006). In J. Georgas, J. W. Berry, F. Van de Vijver, C. Kagitçibasi, \& Y. H. Poortinga, Y. (Eds.), Families across cultures: A 30-nation psychological study (pp. 344-352). Cambridge, UK: Cambridge University Press.

Nasir, N. S. \& Hand, V. (2008). From the court to the classroom: Opportunities for engagement, learning, and identity in basketball and classroom mathematics. The Journal of the Learning Sciences, 17(2), 143179. https://doi.org/10.1080/10508400801986108

Nasir, N. S., \& Cooks, J. (2009). Becoming a Hurdler: How Learning Settings Afford Identities. Anthropology \& Education Quarterly, 40(1), 41-61. https://doi.org/10.1111/j.1548-1492.2009.01027.x

NCTM (2000). Principles and standards for school mathematics. Reston, VA: NCTM.

Nova-Kaltsouni, C. (2018). Oikogeneia kai oikogeneiakes scheseis [Family and familial relationships]. Athens, Greece: Gutenberg.

Ntow, F. D., \& Adler, J. (2019). Identity resources and mathematics teaching identity: An exploratory study. ZDM, 51(3), 419-432. https://doi.org/10.1007/s11858-019-01025-z

Pepin, B., \& Roesken-Winter, B. (Eds.). (2015). From beliefs to dynamic affect systems in mathematics education: exploring a mosaic of relationships and interactions. Cham, Switzerland: Springer. https://doi.org/10.1007/978-3-319-06808-4

Pezdek, K., Berry, T., \& Renno, P. A. (2002). Children's mathematics achievement: The role of parents' perceptions and their involvement in homework. Journal of Educational Psychology, 94(4), 771-777. https://doi.org/10.1037/0022-0663.94.4.771

Radovic, D., Black, L., Williams, J., \& Salas, C. (2018). Towards conceptual coherence in the research on mathematics learner identity: a systematic review of the literature. Educational Studies in Mathematics, 99(1), 21-42. https://doi.org/10.1007/s10649-018-9819-2 
Sfard, A., \& Prusak, A. (2005). Telling Identities: In Search of an Analytical Tool for Investigating Learning as a Cultural Shaped Activity. Educational Researcher, 34(4), 14-22. https://doi.org/10.3102/0013189X034004014

Skovsmose, O. (2005). Foreground and politics of learning obstacles. For the Learning of Mathematics, 25(1), 4-10.

Takeuchi, M. (2018). Power and identity in immigrant parents' involvement in early years mathematics learning. Educational Studies in Mathematics, 97(1), 39-53. https://oi.org/10.1007/s10649-017-9781-4

Turner, E., Dominguez, H., Maldonado, L., \& Empson,S. (2013). English learners' participation in mathematical discussion: shifting positionings and dynamic identities. Journal for Research in Mathematics Education, 44(1), 199-234. https://doi.org/10.5951/jresematheduc.44.1.0199

Van den Heuvel-Panhuizen, M. (2003). The didactical use of models in realistic mathematics education: An example from a longitudinal trajectory on percentage. Educational Studies in Mathematics, 54(1), 935. https://doi.org/10.1023/B:EDUC.0000005212.03219.dc

Wagner, D. \& Herbel-Eisenmann, B. (2009). Re-mythologizing mathematics through attention to classroom positioning. Educational Studies in Mathematics, 72, 1-15. https://doi.org/10.1007/s10649-008-9178-5

Wang, D. B. (2004). Family background factors and mathematics success: A comparison of Chinese and US students. International Journal of Educational Research, 41(1), 40-54. https://doi.org/10.1016/j.ijer.2005.04.013

Wenger, E. (1998). Communities of practice: Learning, meaning, and identity. Cambridge, UK: Cambridge University Press. https://doi.org/10.1017/CBO9780511803932 